\title{
PENGEMBANGAN MODEL PENDIDIKAN KARAKTER PADA PESANTREN BERBASIS MULTIKULTURAL DI PONDOK PESANTREN NGALAH PURWOSARI PASURUAN
}

\author{
Aris Setiawan \& Lailatuz Zahro A.A \\ Fakultas Psikologi Universitas Yudharta Pasuruan \\ arissetiawan@yudharta.ac.id \& kalyla.zahra@yudharta.ac.id
}

\begin{abstract}
Abstrak:
Pendidikan di pondok pesantren merupakan pendidikan berbasis agama, Pondok Pesantren Ngalah Purwosari Pasuruan merupakan Pesantren Berbasis Multikultural yang memiliki model pendidikan yang sangat banyak, diantaranya model pendidikan karakter. Tujuan penelitian ini mengetahui implementasi pendidikan karakter dengan metode kualitatif, menggunakan SEM dengan hasil bahwa Keterlibatan orangtua, dukungan teman sebaya, dan dukungan guru, baik secara simultan maupun parsial, berpengaruh positif terhadap religiusitas dalam model pendidikan karakter pada pesantren berbasis multikultural, ponpes Ngalah Purwosari, Kabupaten Pasuruan. Keterlibatan orangtua, dukungan teman sebaya, dukungan guru, dan religiusitas secara simultan berpengaruh positif terhadap pendidikan karakter dalam model pendidikan karakter pada pesantren berbasis multikultural, ponpes Ngalah Purwosari Kabupaten Pasuruan. Akan tetapi, secara parsial dukungan guru terbukti tidak berpengaruh signifikan terhadap pendidikan karakter.
\end{abstract}

Kata Kunci: Model Pendidikan Karakter, Pesantren, Multikultural.

\begin{abstract}
:
Education in Islamic boarding schools is a religion-based education, Pondok Pesantren Ngalah Purwosari Pasuruan is a Multicultural-Based Islamic Boarding School which has very many educational models, so is the character education model. The purpose of this study discusses how to create characters using qualitative methods, using SEM with the results of research on how to support, support peers, and support teachers, both simultaneously and partially, positively support religiosity in the character education model of the boarding school based on multiculturalism, Islamic Boarding Schools Ngalah Purwosari, Pasuruan Regency. On the basis of assistance, peer support, teacher support, and simultaneous support support positive character education in the character education model of a multicultural-based boarding school, Ngalah Purwosari Islamic Boarding School Pasuruan Regency. However, the partial support of teachers proved to be not significant support for character education.
\end{abstract}

Keywords: Character Education Model, Islamic Boarding School, Multicultural 


\section{Pendahuluan}

Tantangan terbesar dunia saat ini sebenarnya adalah karena adanya pertukaran pandangan, produk, dan unsur-unsur budaya, yang mendorong bangsabangsa di dunia ini untuk hidup saling tergantung (interdependent). ${ }^{1}$ Dampak globalisasi yang tak terelakkan ini, sebagai keniscayaan yang merasuk ke berbagai aspek kehidupan. Apabila Indonesia gagal beradaptasi dengan berbagai kondisi yang tercipta, maka hal yang paling mungkin terjadi adalah penduduk Indonesia yang besar hanya akan menjadi penonton (beban), bukan pemain yang siap bersaing di kancah global. Menurut Megawangi ${ }^{2}$ pentingnya manusia Indonesia memiliki karakter yang kuat, sudah menjadi komitmen para pendiri bangsa, dan dikristalisasikan dalam semangat nation and character building yang diikrarkan pada Sumpah Pemuda, 28 Oktober $1928 .^{3}$ Memungut perspektif teori social cognitive, karakter manusia tidak terbentuk dalam ruang hampa. Karakter, menurut Chaplin, berasal dari bahasa Inggris character, sinonim dengan trait, yang berarti watak atau sifat. Menurut Lickona, pendidikan karakter, menekankan tiga komponen karakter yang baik (components of good character) yaitu pengetahuan tentang moral (moral knowing), perasaan (moral feeling), dan tindakan yang bermoral (moral behavior). Hal ini diperlukan agar peserta didik memahami, merasakan, sekaligus mengerjakan nilai-nilai kebajikan. Oleh sebab itu, pendidikan karakter dapat dimaknai sebagai upaya terencana supaya peserta didik mengenal dan menginternalisasi nilai-nilai karakter (nilai-nilai yang melandasi perilakunya berdasarkan norma agama, kebudayaan, hukum, adat istiadat, dan estetika), sehingga peserta didik dapat sungguh-sungguh berperilaku sebagai manusia seutuhnya. ${ }^{4}$

Menurut Undang-Undang No.20/2003 tentang Sistem Pendidikan Nasional, pendidikan adalah usaha sadar dan terencana untuk mewujudkan suasana belajar dan proses pembelajaran agar peserta didik secara aktif mengembangkan potensi dirinya agar memiliki kekuatan spiritual keagamaan, pengendalian diri, kepribadian, kecerdasan, akhlak mulia, serta keterampilan yang diperlukan dirinya, masyarakat, bangsa dan negara. Sementara itu, karakter, menurut Chaplin, berasal dari bahasa Inggris character, sinonim dengan trait, yang berarti watak atau sifat. ${ }^{5}$ Menurut Lickona, pendidikan karakter, menekankan tiga komponen karakter yang baik (components of good character) yaitu pengetahuan tentang moral (moral knowing), perasaan (moral feeling), dan tindakan yang bermoral (moral behavior). Hal ini diperlukan agar peserta didik memahami,

\footnotetext{
${ }^{1}$ Hangestiningsih, E., Zulfiati, H. M., \& Johan, A. B. Pengantar Ilmu Pendidikan. (Jakarta: Graha Ilmu. 2015), hlm 221.

2 Bakar, Z. A. Teori-teori perkembangan Psikologi Pendidikan. (Jakarta: Chaplin, 2008) hlm 87.

3 Papalia, D. E., \& Feldman, R. D. Human Development Perkembangan Manusia. (Jakarta: Salemba Humanika. 2009) hlm 85.

${ }^{4}$ Chu, S. H., Yang, H., Lee, M., \& Park, S. The impact of institutional pressures on green supply chain management and firm performance: Top management roles and social capital. Sustainability (Switzerland), (Volume 9 Nomor 5 June 2018).

${ }^{5}$ Rakhmawati, A., Nizar, M., \& Rahardjo, K. (2019). Green Supply Chain Management and SME's, A Qualitative Study in Indonesian Marketplace. Journal of International Conference Proceedings, (Volume 2 No. 1, 2019).
} 
merasakan, sekaligus mengerjakan nilai-nilai kebajikan. ${ }^{6}$ Oleh sebab itu, pendidikan karakter dapat dimaknai sebagai upaya terencana supaya peserta didik mengenal dan menginternalisasi nilai-nilai karakter (nilai-nilai yang melandasi perilakunya berdasarkan norma agama, kebudayaan, hukum, adat istiadat, dan estetika), sehingga peserta didik dapat sungguh-sungguh berperilaku sebagai manusia seutuhnya.

Sayangnya, semangat nation and character building dan religiusitas yang diharapkan, tampaknya masih jauh panggang dari api. Banyak sekali fakta yang mengindikasikan tentang hal itu. Padahal karakter dan religiusitas merupakan "modal dasar" membangun peradaban bangsa, terlebih dikaitkan dengan anugerah Tuhan kepada Indonesia, dijadikanNya sebagai bangsa yang multikultur. ${ }^{7}$ Namun di sisi lain, menggunakan cara pandang yang optimistic, multikultural merupakan kekayaan Indonesia, yang mewadahi cara-cara elegan membangun peradaban dengan semangat kebersamaan dan kesetaraan. Oleh sebab itu, karakter dan religiusitas menjadi "kata kunci" yang harus mengiringi seluruh proses pendidikan dan tumbuh kembang generasi ke generasi di Indonesia.

Pembentukan karakter dan religiusitas seiring dengan tumbuh kembang anak, secara formal berlangsung di lembaga-lembaga pendidikan. Lembaga-lembaga pendidikan Islam melalui pondok-pondok pesantren, sudah seharusnya menjadi penggerak terdepan dalam mewadahi dan mendorong pendidikan karakter, sehingga perilaku positif para santri tidak berhenti pada religiusitas yang exclusive. Jika berhenti pada sikap yang demikian, agama apapun, akan mudah menggelincirkan penganutnya untuk menafsirkan yang berbeda sebagai "musuh". 8 Umat Islam harus menunjukkan kualitas rahmatan lil alamin-nya kepada dunia, bukan hanya kepada Indonesia sebagai negara berpenduduk muslim terbesar di dunia, sebab ajaran inti dari karakter yang benar, jelas-jelas mengalir dalam sepenggal kalimat itu. Sikap dan perilaku dari karakter yang benar juga sudah dicontohkan melalui keteladanan Rasulullah Muhammad dimasa hidupnya. ${ }^{9}$

Kristiawan, mengemukakan bahwa Revolusi mental dan pendidikan karakter memiliki peran penting untuk memajukan peradaban manusia. Pada dasarnya, revolusi mental dan pendidikan karakter ditujukan untuk membuat peserta didik menjadi pintar dan mulia. Ini sepertihalnya yang diajarkan di pondok pesantren Ngalah, yang memperbaiki moral melalui pendidikan baik formal atau non formal. ${ }^{10}$ Penelitian lain juga di kemukakan oleh dengan hasil penelitian bahwa model pendidikan karakter yang efektif adalah yang menggunakan pendekatan komprehensif. ${ }^{11}$ Oleh karena itu dalam penelitian ini yang ingin di dikaji terkait

\footnotetext{
6 Santrock, J. W. Konsekuensi Green Supply Chain Management. Jurnal Sistem Informasi Bisnis. Perkembangan Remaja. (Jakarta: Erlangga. 2003). Hlm 165.

7 Ghozali. Aplikasi Analisis Multivariate Dengan Program SPSS. (Semarang: Badan Penerbit Universitas Diponegoro. 2011) hlm 122.

${ }^{8}$ Hangestiningsih, E., Zulfiati, H. M., \& Johan, A. B. Pengantar Ilmu Pendidikan. (Jakarta: Graha Ilmu. 2015), hlm 187.

${ }^{9}$ Sofyan, Y., \& Kurniawan, H. Generasi Baru Mengolah Data Penelitian dengan partial Least Square Path Modeling. (Jakarta: Salemba Infotek. 2011) hlm. 211.

10 J. P. Kamus lengkap psikologi. (Jakarta: RajaGrafindo Persada. 2011) hlm 93.

11 Chu, S. H., Yang, H., Lee, M., \& Park, S. Sustainability (Switzerland), (2017). (Volume 9 Nomor 5 June 2018).
} 
model pengembangan pendidikan karakter, khususnya di pondok pesantren yang identik dengan religiusitas dan multikultural, inilah yang membedakan literatur penelitian sekarang dengan sebelumnya. ${ }^{12}$

Pembentukan karakter dan religiusitas secara simultan sudah diwujudkan oleh KH. M. Sholeh Bahruddin, melalui Pondok Pesantren Ngalah PurwosariPasuruan, yang dirintisnya sejak tahun 1985 silam. ${ }^{13}$ Atas ridho Allah SWT, kini pesantren ini sukses menjadi magnet bagi ribuan santri, sebab tidak hanya mengedepankan pendidikan nonformal, tetapi juga pendidikan formal, baik itu RA (TK) sampai Universitas. Tenaga pendidiknya pun tidak harus dari kalangan muslim, relasi sinergis dengan nonmuslim juga terjalin sangat erat. Semua itu menjadi bukti bahwa fokus pesantren ini sungguh-sungguh ingin membentuk santri yang beriman dan bertaqwa kepada Allah SWT, berakhlakul karimah, santri yang mampu menjawab tantangan zaman, memiliki kepedulian dan kepekaan terhadap masalah agama, pendidikan, sosial, budaya, nilai-nilai kemasyarakatan dan kebangsaan, dengan misi utama rahmatan lil alamin.

Menurut Glock, ada lima macam dimensi religiusitas, yakni a) Dimensi keyakinan, berisi pengharapan-pengharapan dimana orang religius berpegang teguh pada pandangan teologis tertentu dan mengakui kebenaran doktrin-doktrin tersebut; b) Dimensi peribadatan atau praktek ibadah (ritualistic), meliputi perilaku pemujaan, ketaatan, dan hal-hal yang dilakukan orang untuk menunjukkan komitmen terhadap agama yang dianutnya; c) Dimensi pengalaman, berkaitan dengan pengalaman religiusitas, perasaan-perasaan, persepsipersepsi, dan sensasi- sensasi yang dialami seseorang; d) Dimensi pengetahuan agama, berkaitan dengan pengetahuan mengenai dasar-dasar keyakinan, ritus-ritus, kitab suci dan tradisi- tradisi; e) Dimensi pengamalan atau konsekuensi, merujuk pada identifikasi akibatakibat dari keempat dimensi yang telah disebutkan (keyakinan, praktik, pengalaman, dan pengetahuan). ${ }^{14}$

Penelitian ini bertujuan mengembangkan model pendidikan karakter di Pondok Pesantren Ngalah Purwosari-Pasuruan, dengan menganalisis hubungan prediktif antar variabel, yakni keterlibatan orangtua, dukungan teman sebaya, dukungan guru, religiusitas, dan pendidikan karakter. Menurut Chaplin, berasal dari bahasa Inggris character, sinonim dengan trait, yang berarti watak atau sifat. Sedangkan religiusitas berasal dari kata religious, merupakan kata sifat dari religion (agama). ${ }^{15}$

Menurut Chu, Yang, Lee, \& Park, dukungan teman sebaya mengacu pada peer-to-peer learning, yang melibatkan siswa untuk saling memberikan

\footnotetext{
12 Bakar, Z. A. Teori-Teori Perkembangan. hlm 111.

${ }^{13}$ Hsieh, M. M., Chen, C. Y., Hsieh, S. L., Hsieh, S. F., Lee, P. H. Ben, Li, C. T., \& Hsieh, T. J. Separation of phenols from the leaves of Toona sinensis (meliaceae) by capillary electrophoresis. Journal of the Chinese Chemical Society. (Vol 3 No. 2. 2006).

${ }^{14}$ Suldo, S. M., Dedrick, R. F., Shaunessy-Dedrick, E., Fefer, S. A., \& Ferron, J. Development and Initial Validation of the Coping With Academic Demands Scale: How Students in Accelerated High School Curricula Cope With School- Related Stressors. Journal of Psychoeducational Assessment. (Vol. 21 Vol. 2. 2015).

${ }^{15}$ Sulton, A. Kurikulum Pesantren Multikultural (Melacak Muatan Nilai-Nilai Multikultural Dalam Kurikulum Pondok Pesantren Sunan Drajat Banjarwati Paciran Lamongan). ULUL ALBAB Jurnal Studi Islam. (Vol 6, No. 2. 2015: 21-40).
} 
dukungan satu sama lain, baik yang berkaitan dengan masalah-masalah akademik ataupun non-akademik. Menurut Suldo, Dedrick, Shaunessy-Dedrick, Fefer, \& Ferron, (2015), dukungan teman sebaya, mencakup empat tipe, sebagai berikut: a) Emotional support yaitu dukungan berkenaan dengan trust dan love, seperti komunikasi yang dilakukan dengan empati dan perhatian. b) Instrumental support yaitu dukunga pemberian bantuan waktu bagi seseorang, keterampilan, layanan, atau bahkan uang. ${ }^{16}$ c) Appraisal support yaitu dukungan evaluasi umpan balik terhadap perilaku. Dapat dilakukan melalui kritikan yang bersifat positif atau negatif terhadap penampilan atau kinerja serta menyarankan perbaikannya. d) Informational support yaitu dukungan dalam memberikan bimbingan, nasehat, atau informasi yang dapat dijadikan solusi bagi suatu masalah. ${ }^{17}$

Berdasarkan deskripsi di atas, secara umum tujuan dilaksanakannya penelitian ini adalah untuk mengembangkan model pendidikan karakter pada pesantren berbasis multikultural. Adapaun secara khusus tujuan (specific objectives) dari penelitian ini adalah menganalisis pengaruh religiusitas dan keterlibatan orangtua, teman sebaya dan guru terhadap religiusitas dalam model pendidikan karakter pada pesantren berbasis multikultural.

\section{Metode Penelitian}

1. Rancangan Penelitian

Metode penelitian yang digunakan dalam studi ini adalah penelitian survey. Penelitian survey adalah penelitian yang mengambil sampel dari satu populasi dan menggunakan kuesioner sebagai alat pengumpul data yang pokok. Maksud yang ingin dicapai adalah menyajikan penjelasan (explanatory) tentang hubungan kausalitas di antara variabel-variabel penelitian.

Variabel dapat dimaknai sebagai operasionalisasi dari konsep, yaitu konsep yang dapat diamati, diukur, sehingga memungkinkan untuk diteliti secara empiris. Berdasarkan fungsi atau kedudukan dalam hubungan kausalitas, terdapat independent variable (exogenous variable) dan dependent variable (endogenous variable).

2. Populasi, Sampel, Besar Sampel, dan Teknik Pengambilan Sampel

Populasi penelitian ini adalah seluruh santri di Pondok Pesantren Ngalah Purwosari Pasuruan, yang berjumlah 3.059 orang. Sedangkan sampel ditentukan dengan syarat: a) Santri Pondok Pesantren Ngalah Pasuruan; b) Tidak mengalami gangguan kesehatan yang serius atau tidak sedang dalam perawatan kesehatan fisik dan mental; c) Bersedia untuk menjadi subjek penelitian. Jika populasinya finite, mempunyai sumber data yang jelas batasnya secara kuantitatif, maka perhitungan terhadap sample size menurut Bakar, dapat menggunakan rumus sebagai berikut: ${ }^{18}$

N. Z $\alpha 2 \cdot \mathrm{p} \cdot \mathrm{q}$

16 Zuchdi, D. Pengembangan model pendidikan karakter terintegrasi dalam pembelajaran bidang studi di sekolah dasar. Cakrawala Pendidikan. (Bandung: Rineka Perdana. 2010) hlm 61.

${ }^{17}$ Hsieh, M. M., Chen, C. Y., Hsieh, S. L., Hsieh, S. F., Lee, P. H. Ben, Li, C. T., \& Hsieh, T. J. Journal of the Chinese Chemical Society. (Vol 12, No, 2, 2006).

18 Ghozali, L. H. Partial Least Squares : Konsep, Teknik dan Aplikasi Menggunakan Program Smart PLS3.0.31. 


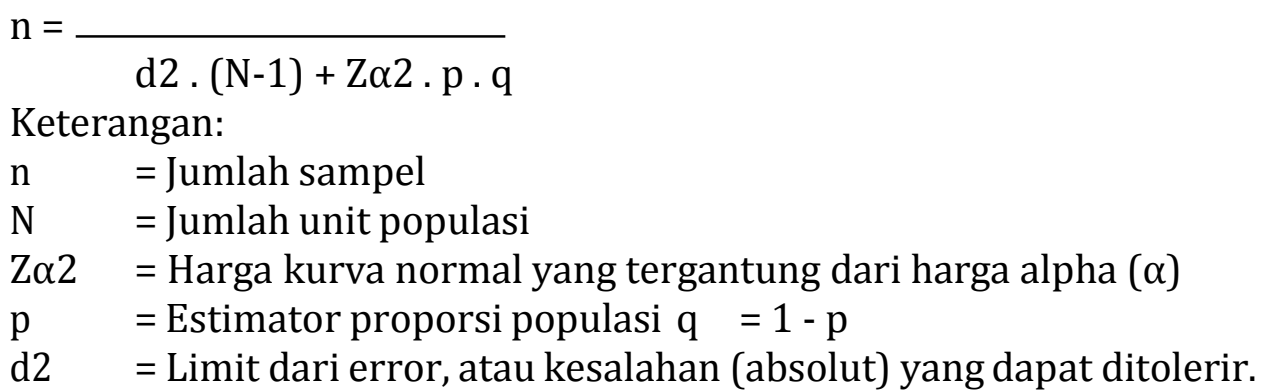

Penelitian ini menggunakan probability sampling, yaitu memberikan peluang yang sama kepada setiap unsur populasi untuk menjadi sampel. Dengan memperhatikan derajat keseragaman (degree of homogenity) dari populasi, maka proses random sampling penelitian ini menggunakan metode stratified random sampling. ${ }^{19}$

3. Instrumen Penelitian

Instrumen pengumpul data penelitian ini adalah angket (questionnaire). Kuesioner merupakan metode lapor diri (self-report), di mana santri sebagai partisipan diminta untuk memberikan respon (baik favorable maupun unfavorable) yang sesuai dengan dirinya, dengan asumsi bahwa santri adalahorang yang paling tahu tentang dirinya dan dapat dipercaya, sehingga penggunaan kuesioner dipandang sebagai instrumen yang paling tepat. Skala yang digunakan pada kuesioner adalah skala Likert yang dimodifikasi dengan enam pilihan jawaban, "sangat tidak setuju (STS), tidak setuju (TS), kurang setuju (KS), cukup setuju (CS), setuju (S), sangat setuju (SS)". Supaya memperoleh instrumen yang berdaya guna untuk penelitian, maka dalam penelitian ini dilakukan proses uji coba (try out) instrumen terlebih dahulu, sebagai upaya tercapainya validitas dan reliabilitas yang tinggi.

4. Uji Model Pengukuran dan Model Struktural

Di dalam PLS-SEM, evaluasi dilakukan melalui dua model, yaitu evaluasi model pengukuran (outer model) dan evaluasi model struktural (inner model). Evaluasi outer model, fokusnya adalah mengevaluasi hubungan antara indikator- indikator dengan konstruknya. ${ }^{20}$ Ukuran seberapa baik validitas konstruk (construct validity) ditentukan oleh kualitas indikatorindikatornya. Hal ini dapat dilihat dari dua ukuran, yakni validitas konvergen (convergent validity) dan validitas diskriminan (discriminant validity). Sementara itu, evaluasi model struktural (inner model) adalah evaluasi untuk mengetahui bagaimana hubungan kausalitas antar latent variables. Dalam hal ini, untuk melihat signifikansi hubungan antarkonstruk (latent variables) dengan cara mengevaluasi nilai t-statistics dan nilai p-value, mengevaluasi nilai

\footnotetext{
19 Jogiyanto. Teori portofolio dan Analisis Investasi. (Yogyakarta: BPEE Yogyakarta. 2009) hlm 22.

${ }^{20}$ Khaerani, R., Pamungkas, P., \& Aeni, S. N. Pengembangan Daya Tarik Wisata Daarus Sunnah Menjadi Wisata Halal. Tourism Scientific Journal. Klein, L. T., Frager, D., Subramanium, A., \& Lowe, F. C. (1998). Use of magnetic resonance urography. Urology. (Vol. 2, No. 1 tahun 2018).
} 
koefisien determinasi (R2), dan memvalidasi model.21

5. Teknik Analisis Data

Penelitian ini menggunakan PLS-SEM, dengan alasan utama terdapat tipe konstruk dengan indikator reflective dan formative dalam satu model penelitian, serta bertujuan mengembangkan teori (prediction-oriented). Adapun garis besar langkah-langkah analisis dalam penelitian ini antara lain: 1) merancang model struktural (inner model), 2) mendefinisikan model pengukuran (outer model), 3) mengkonstruksi diagram jalur, 4) konversi diagram jalur ke sistem persamaan, 5) estimasi: Koefisien jalur, loading dan weight, 6) Evaluasi goodness of fit, dan 7) Pengujian hipotesis. ${ }^{22}$

\section{Pembahasan dan Hasil Penelitian}

PLS-SEM adalah metode analisis SEM alternatif, disebut juga soft modeling karena tidak mengasumsikan data harus dengan pengukuran skala tertentu, tidak mensyaratkan data terdistribusi normal. Jumlah sampel juga lebih moderat (minimal 30-100 kasus), sampel yang besar tentu akan menghasilkan model yang lebih baik. Selain itu, PLS-SEM dapat meng-handle konstruk indikator reflektif dan formatif dalam satu model. ${ }^{23}$

PLS-SEM memiliki kelemahan jika dibandingkan dengan alat-alat analisis data berbasis covariance yang memiliki beragam alat dalam indeks goodness of fit $(G o F)$ - sebab dalam PLS-SEM, evaluasi GoF hanya menyajikan "ukuran tunggal" untuk memvalidasi model. PLS-SEM juga hanya dirancang untuk model recursive (model yang hanya mempunyai satu arah kausalitas). Adapun "hasil" uji PLS-SEM terhadap data, diwakili software XLSTAT-PLS, menyajikan model persamaan struktural sebagai berikut:

\footnotetext{
${ }^{21}$ J. P. Kamus Lengkap Psikologi. In RajaGrafindo Persada. (Jakarta: Graha Ilmu. 2018), hlm 44.

${ }^{22}$ Kristiawan, M. Telaah Revolusi Mental Dan Pendidikan Karakter Dalam Pembentukkan Sumber Daya Manusia Indonesia Yang Pandai Dan Berakhlak Mulia. (Jakarta: Bina Ilmu. 2016), hlm 12. ${ }^{23}$ Chin, W. W. The partial least squares approach for structural equation modeling. In Modern methods for business research. (Bandung: Aksara Ilmi. 1998) hlm 81.
} 


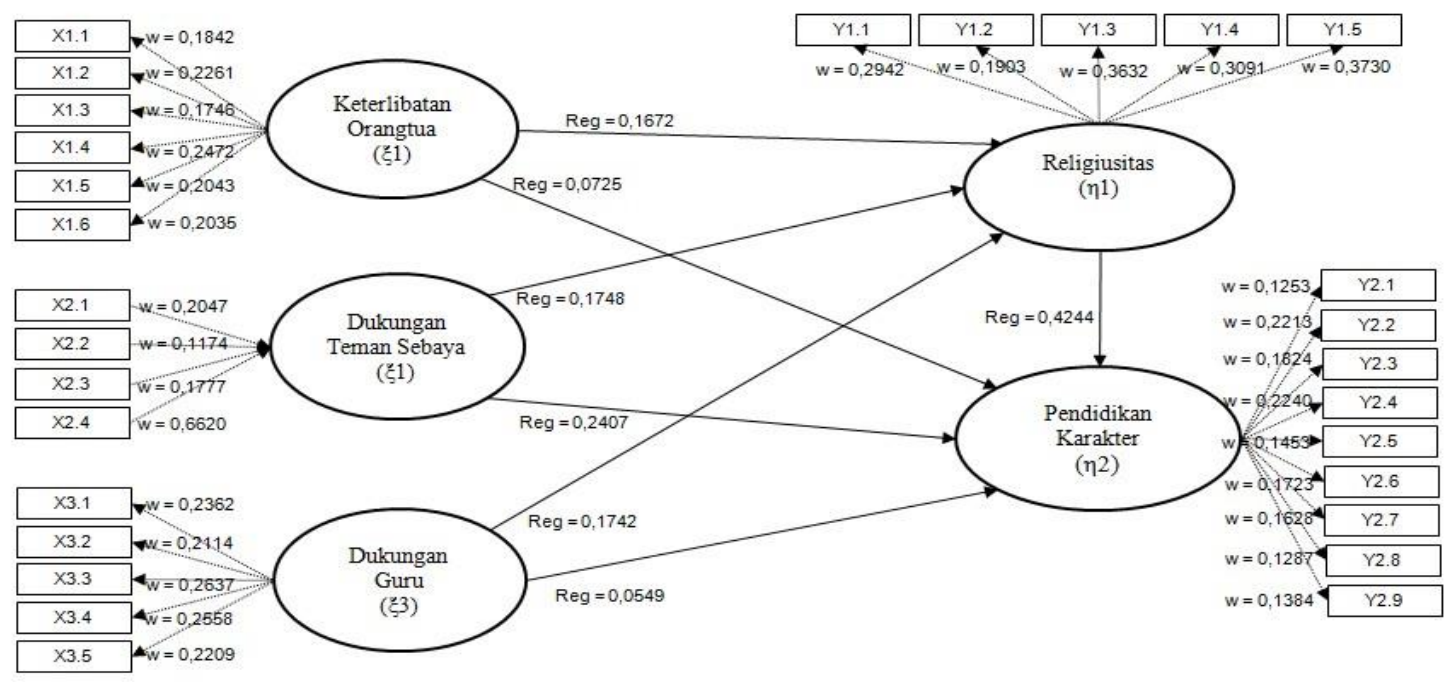

Gambar Evaluasi Model Pendidikan Karakter pada Pesantren Berbasis Multikultural di Pondok Pesantren Ngalah Purwosari-Kabupaten Pasuruan.

\section{Evaluasi Model Pengukuran (outer model)}

Evaluasi ini difokuskan untuk menilai validitas dan reliabilitas setiap konstruk. Apabila dilihat dari nilai standardized loadings dan cross loadings pada tiap konstruk reflektif, semuanya di atas 0,4 yang berarti dalam kriteria valid. Demikian pula dilihat dari Composite Reliability nilai D.G. Rho (PCA), semuanya juga di atas 0,7 yang berarti reliabilitasnya dapat diterima. Pada konstruk Dukungan Teman Sebaya, semua indikator memiliki nilai VIF $<10$, dan nilai tolerance $>0,10$ yang berarti tidak ada masalah multikolinearitas. ${ }^{24}$

\section{Evaluasi Model Struktural (inner model)}

a. Evaluasi Model Struktural Pertama

Evaluasi model ini untuk melihat pengaruh variabel keterlibatan

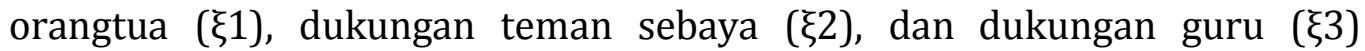
terhadap religiusitas $(\eta 1)$. Berdasarkan nilai probabilitas F-statistics pada tabel $R^{2}$ (Religiusitas $\left./ 1\right)$, terbukti nilai $p$-value $0,000<\alpha(\alpha=0,05)$, yang berarti "ada pengaruh yang signifikan" ketiga variabel prediktor tersebut terhadap religiusitas ( $\eta 1)$. Berdasarkan pengujian secara individual masing-masing konstruk terhadap religiusitas $(\eta 1)$, nilai $t$ statistics keterlibatan orangtua ( $\xi 1)$ sebesar 2,8694; dukungan teman

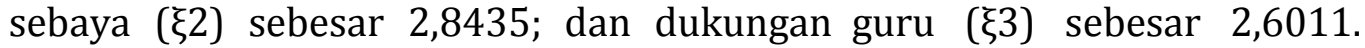
Tampaknya, setiap konstruk menampilkan nilai $t$ - statistics $>\mathrm{t}$-tabel 1,96 (t-tabel signifikansi $5 \%=1,96$ ), artinya "masing- masing" variabel prediktor berpengaruh signifikan terhadap religiusitas ( $\eta 1$ ). Pada tabel Impact and contribution of the variables to Religiusitas (Dimension 1),

${ }^{24}$ Krüger, M., \& Frenzel, P. Effects of $\mathrm{N}$-fertilisation on $\mathrm{CH} 4$ oxidation and production, and consequences for $\mathrm{CH} 4$ emissions from microcosms and rice fields. Global Change Biology. (Jurnal Eqiubment Vol. 3 No. 4 tahun 2003). 
tampak dukungan guru ( $\xi 3)$ memberikan kontribusi terbesar $(35,9014)$, disusul dukungan teman sebaya ( $\xi 2)$ sebesar 33,5525, dan keterlibatan orangtua $(\xi 1)$ memberikan kontribusi yang paling kecil $(30,5460)$.

b. Evaluasi Model Struktural Kedua

Evaluasi model ini untuk melihat pengaruh variabel keterlibatan

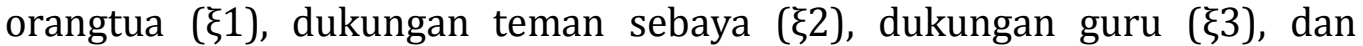
religiusitas ( $\eta 1$ ) terhadap pendidikan karakter ( $\eta 2)$. Berdasarkan nilai probabilitas F-statistics pada tabel $R^{2}$ (Pendidikan Karakter/1), terbukti nilai $p$ - value $0,000<\alpha(\alpha=0,05)$, yang berarti "ada pengaruh yang signifikan" keempat variabel tersebut terhadap pendidikan karakter ( $\eta 2$ ). Berdasarkan pengujian secara individual masing-masing konstruk terhadap pendidikan karakter ( $\eta 2$ ), nilai $t$-statistics keterlibatan orangtua ( $\xi 1)$ sebesar 1,4214; dukungan teman sebaya ( $\xi 2)$ sebesar 4,4701; dukungan guru ( $\xi 3$ ) sebesar 0,9368; dan religiusitas ( $\eta 1$ ) sebesar 9,0032. Tampaknya, hanya dukungan guru yang tidak signifikan, karena menampilkan nilai t-statistics < t-tabel 1,96, sementara tiga variabel lainnya berpengaruh signifikan terhadap pendidikan karakter ( $\eta 2$ ). Pada tabel Impact and contribution of the variables to Pendidikan Karakter (Dimension 1), tampak religiusitas ( $\eta 1$ ) memberikan kontribusi terbesar $(60,5286)$, disusul dukungan teman sebaya

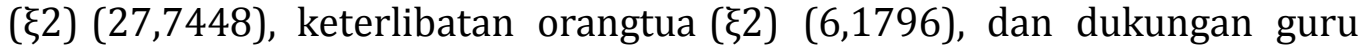
(६3) memberikan kontribusi yang paling kecil $(5,5471)$.

\section{Uji Kesesuaian Model (goodness of fit)}

Index ini merupakan ukuran tunggal yang dikembangkan untuk mengevaluasi outer model dan inner model secara keseluruhan (overall fit). Global fit measure yang direkomendasikan oleh Kushler, (2002); dalam (Sofyan \& Kurniawan, 2011) adalah "GoF statistics $(0<\mathrm{GoF}<1)$, nilai 0,1 (GoF kecil); 0,25 (GoF moderate); dan 0,36 (GoF besar). Dari tabel Goodness of fit index (1) penelitian ini diperoleh GoF absolute sebesar 0,3954 (terbukti lebih besar dari 0,36). Berdasarkan penggolongan GoF tersebut, maka kecocokan model penelitian ini adalah besar. Ukuran GoF yang besar menunjukkan tingginya derajat kecocokan antara data dan model. Artinya, model cukup menjelaskan atau fit dengan data empiris.

\section{Pembahasan}

Hasil uji hipotesis sebagaimana disajikan pada dua evaluasi model struktural di atas, secara simultan semuanya diterima. Namun secara parsial, dari tujuh jalur (path) prediksi, satu di antaranya ditolak, yaitu "pengaruh dukungan guru terhadap pendidikan karakter" terbukti tidak signifikan.

1. Pengaruh keterlibatan orangtua, dukungan teman sebaya, dan dukungan guru terhadap religiusitas dalam model pendidikan karakter pada pesantren berbasis multikultural.

Hasil uji hipotesis menunjukkan, "ada pengaruh keterlibatan orangtua, dukungan teman sebaya, dan dukungan guru, secara simultan, terhadap religiusitas dalam model pendidikan karakter pada pesantren berbasis multikultural." Diterimanya hipotesis secara simultan ini, mendukung pandangan 
teoretisi terdahulu bahwa beliefs siswa tidak berada di dalam ruang hampa, namun dibentuk oleh persepsi terhadap lingkungan belajar, dan lingkungan sosial yang utama bagi siswa adalah orangtua, teman sebaya, dan guru. Namun, pengaruh ketiga variabel tersebut terhadap religiusitas masih tergolong "lemah". Hal ini dapat dilihat dari koefisien determinasi $\left(\mathrm{R}^{2}\right)$ hanya sebesar 0,1772. Terkait hal ini, menurut (Chin, 1998) dalam (Imam Ghozali, 2014), nilai $\mathrm{R}^{2}$ sebesar 0,67, 0,33, dan 0,19 menunjukkan model yang kuat, moderate, dan lemah. Nilai $\mathrm{R}^{2}$ sebesar itu $(0,1772)$ juga berarti bahwa variabel religiusitas dapat dijelaskan oleh ketiga variabel prediktor tersebut secara simultan hanya sebesar $17,72 \%$. Sisanya $(82,28 \%)$ mengisyaratkan adanya pengaruh variabelvariabel lain, di luar model ini.

2. Pengaruh keterlibatan orangtua, dukungan teman sebaya, dukungan guru, dan religiusitas terhadap pendidikan karakter dalam model pendidikan karakter pada pesantren berbasis multikultural.

Hasil uji hipotesis menunjukkan, "ada pengaruh keterlibatan orangtua, dukungan teman sebaya, dukungan guru, dan religiusitas secara simultan, terhadap pendidikan karakter dalam model pendidikan karakter pada pesantren berbasis multikultural." Dari empat variabel prediktor tersebut, variabel religiusitas menunjukkan kontribusi yang paling besar, dan dukungan guru menunjukkan pengaruh yang paling kecil sekaligus tidak signifikan terhadap pendidikan karakter. Ditinjau dari pengaruh keempat variabel tersebut terhadap pendidikan karakter dapat dikategorikan "moderate", ditunjukkan koefisien determinasi $\left(\mathrm{R}^{2}\right)$ sebesar 0,3855. Nilai $\mathrm{R}^{2}$ sebesar itu juga berarti bahwa pendidikan karakter dapat dijelaskan oleh keempat variabel prediktor tersebut secara simultan sebesar 38,55\%. Sementara sisanya $(61,45 \%)$ mengisyaratkan adanya pengaruh variabel prediktor lainnya, di luar model ini.

Temuan ini sangat menarik, sebab terbukti di antara tiga dukungan sosial, dukungan teman sebaya memiliki kontribusi paling unggul terhadap pendidikan karakter. ${ }^{25}$ Ditinjau dari perspektif teori-teori psikologi perkembangan pesatnya pertumbuhan remaja beriringan dengan pilihan lebih banyak menyediakan waktu bersama teman-teman sebaya. ${ }^{26}$ Dengan kata lain, pengaruh teman sebaya jauh lebih bermakna bagi remaja. ${ }^{27}$ Selanjutnya, terkait temuan besarnya pengaruh religiusitas terhadap pendidikan karakter, menurut Santrock, bahwa mereka yang berada pada tahap perkembangan formal operasional, tidak lagi melihat perwujudan identitas keagamaan dalam tingkah laku individu, tetapi lebih memperhatikan bukti keberadaan keyakinan dan pendirian dalam diri seseorang. Dengan demikian, sebagai model akhir dari penelitian ini, kontribusi dukungan sosial terhadap religiusitas, pada gilirannya memiliki daya

25 Ghozali. Aplikasi Analisis Multivariate Dengan Program SPSS. hlm 210.

${ }^{26}$ Chin, W. W. The partial least squares approach for structural equation modeling. In Modern methods for business research. (Vol. 16 No. 3 tahun 1998).

27 Lickona, T.. The Teacher's Role in Character Education. Journal of Education. Megawangi, R. (2004). Pendidikan Karakter (Solusi yang Tepat untuk Membangun Bangsa). Uakarta: Indonesia Herritage Foundation. 2017). Hlm 221. 
prediksi terhadap berbagai hasil psikologis yang muncul dalam pendidikan karakter, baik di level intraindividual, interpersonal, maupun sosial. ${ }^{28}$

\section{Penutup}

Mengacu pada analisis inferensial, yaitu hasil uji statistik terhadap hipotesis yang diajukan, dapat ditarik kesimpulan sebagai berikut:

Keterlibatan orangtua, dukungan teman sebaya, dan dukungan guru, baik secara simultan maupun parsial, berpengaruh positif terhadap religiusitas dalam model pendidikan karakter pada pesantren berbasis multikultural, ponpes Ngalah Purwosari, Kabupaten Pasuruan.

Keterlibatan orangtua, dukungan teman sebaya, dukungan guru, dan religiusitas secara simultan berpengaruh positif terhadap pendidikan karakter dalam model pendidikan karakter pada pesantren berbasis multikultural, ponpes Ngalah Purwosari, Kabupaten Pasuruan. Akan tetapi, secara parsial, dukungan guru terbukti tidak berpengaruh signifikan terhadap pendidikan karakter.

Berdasarkan kesimpulan hasil uji hubungan prediktif antarvariabel tersebut, dapat dinyatakan bahwa pendidikan karakter sangat dipengaruhi oleh religiusitas, di mana religiusitas dipengaruhi oleh dukungan guru, teman sebaya, dan keterlibatan orang tua.

\section{Daftar Pustaka}

Bakar, Z. A. Teori-teori perkembangan Psikologi Pendidikan. (Jakarta: Chaplin, 2008). Chin, W. W. The partial least squares approach for structural equation modeling. In Modern methods for business research. (Bandung: Aksara Ilmi. 1998).

Chu, S. H., Yang, H., Lee, M., \& Park, S. The impact of institutional pressures on green supply chain management and firm performance: Top management roles and social capital. Sustainability (Switzerland), Volume 9 Nomor 5 June 2018.

Ghozali, L. H. Partial Least Squares: Konsep, Teknik dan Aplikasi Menggunakan Program Smart PLS3.0. (Semarang: Universita. 2014).

Ghozali. Aplikasi Analisis Multivariate Dengan Program SPSS. (Semarang: Badan Penerbit Universitas Diponegoro. 2011).

Hangestiningsih, E., Zulfiati, H. M., \& Johan, A. B. Pengantar Ilmu Pendidikan. (Jakarta: Graha Ilmu. 2015).

Hsieh, M. M., Chen, C. Y., Hsieh, S. L., Hsieh, S. F., Lee, P. H. Ben, Li, C. T., \& Hsieh, T. J. Separation of phenols from the leaves of Toona sinensis (meliaceae) by capillary electrophoresis. Journal of the Chinese Chemical Society. (Vol 12, No, 2 , 2006).

Jogiyanto. Teori portofolio dan Analisis Investasi. (Yogyakarta: BPEE Yogyakarta. 2009).

Jon. P. Kamus lengkap Psikologi. (Jakarta: RajaGrafindo Persada. 2011).

\footnotetext{
${ }^{28}$ Moh. Wardi. "Penerapan Nilai Pendidikan Agama Islam dalam Perubahan Sosial Remaja." TADRIS: Jurnal Pendidikan Islam 7.1 (2013): 31-44.
} 
Khaerani, R., Pamungkas, P., \& Aeni, S. N. Pengembangan Daya Tarik Wisata Daarus Sunnah Menjadi Wisata Halal. Tourism Scientific Journal. Klein, L. T., Frager, D., Subramanium, A., \& Lowe, F. C. (1998). Use of magnetic resonance urography. Urology. (Vol. 2, No. 1 tahun 2018).

Kristiawan, M. Telaah Revolusi Mental Dan Pendidikan Karakter Dalam Pembentukkan Sumber Daya Manusia Indonesia Yang Pandai Dan Berakhlak Mulia. (Jakarta: Bina Ilmu. 2016).

Krüger, M., \& Frenzel, P. Effects of N-fertilisation on $\mathrm{CH} 4$ oxidation and production, and consequences for $\mathrm{CH} 4$ emissions from microcosms and rice fields. Global Change Biology. (Jurnal Eqiubment Vol. 3 No. 4 tahun 2003).

Lickona, T.. The Teacher's Role in Character Education. Journal of Education. Megawangi, R. (2004). Pendidikan Karakter (Solusi yang Tepat untuk Membangun Bangsa). (Jakarta: Indonesia Herritage Foundation. 2017).

Papalia, D. E., \& Feldman, R. D. Human Development Perkembangan Manusia. (Jakarta: Salemba Humanika. 2009).

Rakhmawati, A., Nizar, M., \& Rahardjo, K. Green Supply Chain Management and SME's, A Qualitative Study in Indonesian Marketplace. Journal of International Conference Proceedings, (Volume 2 No. 1, 2019).

Santrock, J. W. Konsekuensi Green Supply Chain Management. Jurnal Sistem Informasi Bisnis. Perkembangan Remaja. (Vol 12 No. 2. 2011).

Sofyan, Y., \& Kurniawan, H. Generasi Baru Mengolah Data Penelitian dengan partial Least Square Path Modeling. (Jakarta: Salemba Infotek. 2011).

Suldo, S. M., Dedrick, R. F., Shaunessy-Dedrick, E., Fefer, S. A., \& Ferron, J. Development and Initial Validation of the Coping With Academic Demands Scale: How Students in Accelerated High School Curricula Cope With SchoolRelated Stressors. Journal of Psychoeducational Assessment. (Vol. 21 No. 2. 2015).

Sulton, A. Kurikulum Pesantren Multikultural (Melacak Muatan Nilai-Nilai Multikultural Dalam Kurikulum Pondok Pesantren Sunan Drajat Banjarwati Paciran Lamongan). ULUL ALBAB Jurnal Studi Islam. (Vol 6, No. 2. 2015).

Zuchdi, D. Pengembangan model pendidikan karakter terintegrasi dalam pembelajaran bidang studi di sekolah dasar. Cakrawala Pendidikan. (Bandung: Rineka Perdana. 2010).

Wardi, Moh. "Penerapan Nilai Pendidikan Agama Islam dalam Perubahan Sosial Remaja." TADRIS: Jurnal Pendidikan Islam 7.1 (2013): 31-44. 